\title{
Two new species of the genus Rhyacophila Pictet (Trichoptera, Rhyacophilidae) from Korea and Japan
}

\author{
TAKAO NOZAKI ${ }^{1, *} \&$ SUN-JIN PARK ${ }^{2}$ \\ '3-16-15, Midorigaoka, Ninomiya-machi, Naka-gun, Kanagawa, 259-0132 Japan. \\ ”takao.nozaki@nifty.com; @ ittps://orcid.org/0000-0001-6492-6513 \\ ${ }^{2}$ Department of Life Science, Kyonggi University, Suwon 16227, Korea. \\ झ"sjpark935@gmail.com; ○ https://orcid.org/0000-0002-0799-8980 \\ "Corresponding author. takao.nozaki@nifty.com
}

\begin{abstract}
Two new species of the genus Rhyacophila Pictet, R. kangae Park \& Nozaki sp. nov. and R. yamamotoi Nozaki sp. nov., are described from Korea and Japan, respectively. Both species belong to the Rhyacophila nigrocephala Species Group, and their genitalic morphology is very similar to those of $R$. confissa Botosaneanu 1970 and $R$. vicina Botosaneanu 1970 described from the Korean Peninsula. These four species can be distinguished from each other by the shape of the complex of preanal appendages and apicodorsal lobe of segment IX in males, and by the shape of the vaginal apparatus in females. Males of the two new species bear larger compound eyes in proportion to the head widths than those of $R$. confissa and R. vicina.
\end{abstract}

Key words: descriptions, male, female, Rhyacophila nigrocephala Species Group, eye size

\section{Introduction}

The genus Rhyacophila Pictet 1834 is one of the largest genera in Trichoptera, composed of more than 800 species in the Nearctic, Holarctic, and Oriental Biogeographic Regions (Morse 2021). In Japan and Korea, 64 species and 27 species of this genus are known, respectively (Park \& Kong 2020; Nozaki 2021). The Rhyacophila nigrocephala Species Group Ross 1956 is distributed in the Oriental and Palearctic Biogeographic Regions (Schmid 1970; Sun 2017), and a total of 10 species of this Group are known from Japan and Korea (Hattori 2005; Park \& Kong 2020): Rhyacophila confissa Botosaneanu 1970 (Korea), Rhyacophila formosana Ulmer 1927 (Japan), Rhyacohila kawamurae Tsuda 1940 (Japan \& Korea), Rhyacophila kuwayamai Schmid 1970 (Japan), Rhyacophila lata Martynov 1918 (Korea), Rhyacophila manuleata Martynov 1934 (Korea), Rhyacophila nigrocephala Iwata 1927 (Japan), Rhyacophila nipponica Navás 1933 (Japan), Rhyacohila shikotsuensis Iwata 1927 (Japan), and Rhyacophila vicina Botosaneanu 1970 (Korea). However, the taxonomic study of the genus Rhyacophila in both countries remains insufficient (Hattori 2005; Park \& Kong 2020), and there are some records of unidentified species belonging to the $R$. nigrocephala Species Group (e.g., Hattori 2005; Kang 2020).

Recently, Kang (2020) recorded an unidentified species similar to R. confissa and $R$. vicina. Rhyacophila confissa and $R$. vicina, originally described from North Korea, are very similar to each other in male and female genitalia (Botosaneanu 1970) and have been commonly found in South Korea (Park \& Kong 2020). Yamamoto et al. (in press) recorded an unidentified species similar to $R$. confissa and $R$. vicina from Shikoku, western Japan. We examined those specimens and other materials collected from Korea and Japan and recognized two new species. In this paper, we describe these two new species from Korea and Japan and also provide illustrations and photographs of $R$. confissa and $R$. vicina for comparison. 


\section{Materials and methods}

Associations of males and females were based on similar general body characters when they were collected together multiple times. Male and female genitalia were figured after being cleared in a $10 \%$ solution of $\mathrm{KOH}$. Morphological terminology used in this study mainly follows Schmid (1970), Sun (2017), and Arefina (2001). The width of each compound eye and the distance between eyes ( $a$ and $b$ in Fig. 1F) were measured by binocular microscopy using an ocular micrometer. Depositories of specimens used in this study are abbreviated as follows: Kanagawa Prefectural Museum of Natural History, Odawara, Japan (KPM-NK); Minakuchi Kodomo-no-mori Nature Center, Shiga (MITR); Natural History Museum and Institute, Chiba, Japan (CBM-ZI); National Institute of Biological Resources, Incheon, Korea (NIBR); and personal collections of N. Kawase (NK), S.-J. Park (SJP), and T. Nozaki $(\mathrm{TN})$.

\section{Species descriptions}

\section{Rhyacophila kangae Park \& Nozaki sp. nov.}

(Figs 1, 4, 9)

Rhyacophila sp. 3: Kang 2020, 232-233, male (photographs), Korea.

Diagnosis. This species belongs to the Rhyacophila nigrocephala Species Group (Ross 1956). The male genitalia are similar to those of $R$. confissa and $R$. vicina, but the male of $R$. kangae sp. nov. is distinguishable from those of the latter two species by the shape of the complex of preanal appendages and apicodorsal lobe of segment IX: In dorsal aspect, the two lobes are widely separated from each other, forming a large U-shape in $R$. kangae sp. nov. (Fig. 1B), but they form a narrow slit in R. confissa and R. vicina (Figs. 2B, 3B). Furthermore, the male of R. kangae sp. nov. bears large compound eyes in proportion to its head width when compared with those of $R$. confissa and $R$. vicina: $0.37-0.45$ in $R$. kangae, but $0.23-0.31$ in $R$. confissa and $R$. vicina (Figs. 1F a b, 2C, 3C). The female genitalia are similar to those of $R$. confissa and $R$. vicina but can be distinguished by the shape of the vaginal apparatus: In ventral aspect, the posterior process of the vaginal apparatus is long and rectangular in $R$. kangae sp. nov. (Fig. 4F), but that of $R$. confissa bears an 8-shaped unpigmented part apicoventrally (Fig. 6B), and that of $R$. vicina is constricted at $2 / 5$ from the posterior apex (Fig. 7B). The male and female of $R$. kangae sp. nov. are also similar to those of a Japanese species, $R$. yamamotoi sp. nov., but they are distinguished by the characters given in the diagnosis for that species, below.

Adult. Specimens in alcohol mostly dark brown, but tibiae and tarsi of all legs light brown. Forewings each $12.2-13.5 \mathrm{~mm}$ in male $(\mathrm{n}=6), 13-14.8 \mathrm{~mm}$ in female $(\mathrm{n}=2)$. Ratio of width of eye to distance between eyes $(\mathrm{a} / \mathrm{b}$ in Fig. 1F) 0.37-0.45 in male $(\mathrm{n}=6), 0.25-0.33$ in female $(\mathrm{n}=6)$.

Male genitalia. Segment IX (IX) longitudinally short in lateral aspect (Fig. 1A), ventral half longer than dorsum; membranous along midline in dorsal aspect (Fig. 1B). Complex of pair of preanal appendages and apicodorsal lobe of segment IX (com.) bilobed from about basal 2/5, widely separated, large, U-shaped in dorsal aspect (Fig. 1B); each lobe finger-like in lateral aspect (Fig. 1A), with 3 tiny teeth apicomesally (2 dorsal, 1 ventral, inset for Fig. 1A). Anal sclerites (a.s.) fused basally, bilobed apically, each round apex with minute black denticles dorsally. Apical band (a.b.) long, curved posterad, dorsal margin connected to base of anal sclerite; ventral margin connected to base of sagittal appendage (s.a.) of tergal band (Fig. 1A); sagittal appendage trapezoidal in dorsal and ventral aspects (Fig. 1C). Basal segment of each inferior appendage (i.a.) thick in lateral aspect (Fig. 1A); posteromesal angle triangular, directed mesad in dorsal aspect (Fig. 1B); mesal face with ridged tendon (t.i.a.) along midline, extending to phallotheca (pha.) (Figs 1A, 1D). Distal segment of each inferior appendage bilobed, dorsal lobe club-like in lateral aspect (Figs 1A, 1D), ventral lobe semicircular in lateral aspect, both lobes with minute spines apicomesally. In phallic apparatus (Fig. 1E), aedeagus (ae.) bottle-shaped in dorsal and ventral aspects; parameres (para.) slender, club-like, apices curve laterad, and with tiny spines.

Female genitalia. Segment VIII (VIII) annular, but semi-membranous along dorsal and ventral midlines, with pair of dorsal weakly sclerotized extensions (Fig. 4C); pair of apodemal rods reaching posterior end of segment VI. Segment IX (IX) membranous, with pair of strongly sclerotized bands dorsolaterally extending into segment VI as 
apodemal rods (Fig. 4B, ap. IX); fused with segment X (X) ventrally, pair of ventrolateral sclerotized bands extending to segment X (Fig. 4B). Segment X slender, with pair of strongly sclerotized bands dorsolaterally; fused with segment XI (XI) (Fig. 4B). In vaginal apparatus, processus spermathecae (p.s.) claw-like in lateral aspect (Fig. 4E), semicircular in ventral aspect (Fig. 4F); posterior process (p.p.) long rectangular in ventral aspect, more than 3 times longer than anterior width, face-down and saucer-shaped in lateral aspect (Fig. 4E).

Immature stages. Unknown.

Holotype. Male (in alcohol), Bangtaecheon Stream, Jindong-ri, Girin-myeon, Inje-gun, Gangwon-do, Korea, $38.024^{\circ} \mathrm{N}, 128.472^{\circ} \mathrm{E}$, alt. $690 \mathrm{~m}$, 23.v.2018, MS. Kang (net sweeping) (NIBR0000935610).

Paratypes. 1 male, 1 female, same data as the holotype (NIBR0000935608-0000935609); 4 males, 1 female, Samil River, Sanae-myeon, Hwacheon-gun, Gangwon-do, Korea, 10.vi.2014, T. Ito (net sweeping) (CBM-ZI 0180236-0180240).

Other specimens examined. KOREA: 2 males, 4 females, Gyebangsan, Gangwon-do, 11.vi.2014, T. Ito (net sweeping) (1 male, 2 females: SJP; 1 male, 2 females: TN).

Etymology. This species is dedicated to Ms. Mi-Sook Kang, who gifted us valuable specimens and information concerning Korean caddisflies, including this species.

Distribution. The Korean Peninsula (Gangwon-do, South Korea).

Remarks. This species was found in Gangwon-do, South Korea, where both $R$. confissa and $R$. vicina are distributed (Fig. 9). One of the sites where $R$. confissa was collected in this study is only $1.4 \mathrm{~km}$ from the type locality of $R$. kangae sp. nov. in the same stream (Bangtaecheon Stream). Although the genitalic morphology of the new species is similar to those of $R$. confissa and $R$. vicina, the differences in diagnostic characters described above are stable.

The male of R. kangae sp. nov. bears large compound eyes in proportion to its head width when compared with those of males of $R$. confiss $a$ and $R$. vicina, and also with those of females of these three species. The sexual dimorphism in the size of compound eyes observed in this new species suggests that the mating behavior of this species may differ from that of $R$. confissa and $R$. vicina.

\section{Rhyacophila yamamotoi Nozaki sp. nov.}

(Figs 5, 8, 9)

Rhyacophila sp. B: Morita 2009, 6-7, list.

Rhyacophila sp. 4: Kawase \& Morita 2010, 36, list

Rhyacophila sp. 3: Yamamoto \& Ito 2014, 7, list.

Diagnosis. Male and female of this species are most similar to those of $R$. kangae sp. nov. but can be distinguished by characters of the genitalic morphology. In males, the apex of each preanal appendage of this species is weakly bilobed apically in lateral aspect (Fig. 8B) but is rounded in R. kangae (Fig. 1A). Each paramere is expanded subapically in this species (Fig. 8E) but is club-like in R. kangae (Fig. 1E). In the female, the posterior process of the vaginal apparatus of this species is broader and thicker than that of $R$. kangae (Figs 4E, 4F, 5E, 5F). In Japan, the male genitalia of this species are somewhat similar to that of Rhyacophila kawamurae in lateral aspect, especially in the shape of the inferior appendages, but can be easily distinguished by the shape of the complex of a pair of preanal appendages and the apicodorsal lobe of segment IX in dorsal aspect: These are bilobed from the basal 1/3-1/2 in this species but bearing only a minute apical notch in R. kawamurae (Tsuda 1940, fig. 17).

Adult. Specimens in alcohol mostly dark brown to black, but legs light brown. Forewings each 8.0-11.5 mm in male $(\mathrm{n}=10), 10.2-11.0 \mathrm{~mm}$ in female $(\mathrm{n}=7)$. Ratio of width of eye to distance between eyes $(\mathrm{a} / \mathrm{b}$ in Fig. 1F) $0.33-0.40$ in male $(n=10)$ (Fig. 8A), 0.24-0.30 in female $(n=8)$.

Male genitalia. Segment IX longitudinally short in lateral aspect (Fig. 8B), ventral half longer than dorsum; membranous along midline in dorsal aspect (Fig. 8C). Complex of pair of preanal appendages and apicodorsal lobe of segment IX bilobed from basal 1/3-1/2, widely separated, large, U-shaped in dorsal aspect (Fig. 8C); in lateral aspect each lobe rectangular, apex slightly concave (Fig. 8B); with 2 teeth apicomesally, dorsal one small, ventral one tiny (inset of Fig. 8B). Anal sclerites fused basally, bilobed, each round apex with minute black denticles dorsally (Fig. 8C). Apical band long, curved posterad, ventral margin connected to sagittal appendage of tergal band (Fig. 8B); sagittal appendage round trapezoidal in dorsal and ventral aspects. Basal segment of each inferior appendage 
thick in lateral aspect (Figs 8B, 8D); mesal face with ridged tendon longitudinally, extending to phallotheca (Figs 8B, 8D); posteromesal angle acute, directed mesad in dorsal aspect (Fig. 8C). Distal segment of each inferior appendage bilobed (Figs. 8B, 8D); both lobes club-like in lateral aspect, with minute spines apicomesally (Fig. 8D). In phallic apparatus, aedeagus bottle-shaped in dorsal and ventral aspects (Fig. 8E); with pair of parameres, each broadened subapically, with tiny spines apically in dorsal aspect (Fig. 8E).

Female genitalia. Segment VIII annular, but semi-membranous along dorsal midline, with pair of dorsal weakly sclerotized extensions (Fig. 5C); pair of apodemal rods reaching posterior end of segment VI. Segment IX membranous, with pair of dorsolateral apodemal rods extending into segment VI; fused with segment X ventrally, with pair of ventrolateral sclerotized band extending to segment X. Segment X slender, with pair of strongly sclerotized bands dorsolaterally; fused with segment XI. In vaginal apparatus, processus spermathecae claw-like in lateral aspect (Fig. 5E), semicircular in ventral aspect (Fig. 5F); posterior process tongue-like in ventral aspect (Fig. 5F), not more than 3 times longer than anterior width, elliptical in lateral aspect.

Immature stages. Unknown.

Holotype. Male (in alcohol). Namakusa-dani, Odamiyama, Uchiko-cho, Ehime, Shikoku, Japan, $33.560^{\circ} \mathrm{N}$, $132.918^{\circ}$ E, alt. $1225 \mathrm{~m}, 11-20 . v .2020$, E. Yamamoto (Malaise trap) (CBM-ZI 0180217).

Paratypes. 10 males, 2 females, same data as the holotype (CBM-ZI 0180218-0180229), 6 males, same data as the holotype excepting the collection period 11-20.vi.2020 (CBM-ZI 0180230-0180235); 1 male, 1 female, Izugatani-yama, Nishidani, Kumakogen-cho, Ehime, Japan, 1-10.v.2018, E. Yamamoto (Malaise trap) (NIBR0000935602-0000935603); 5 males, 2 females, same locality, 11-20.v.2018, E. Yamamoto (Malaise trap) (KPM-NK); 4 males, same locality, 21-31.v.2018, E. Yamamoto (Malaise trap) (NIBR0000935604-0000935607).

Other specimens examined. JAPAN: Honshu: Shizuoka: 1 male, tributary of Nishigochi-gawa, Yokosawa, Aoi-ku, Shizuoka-shi, alt. 550 m, 5.v.2006, T. Nozaki (net sweeping) (TN). Mie: 4 males, Sakashita, Kameyamashi, 14.v.2006, N. Kawase (net sweeping) (MITR-20090042); 10 males, Ojigahata, Taga-cho, alt. 600 m, 19.v8.vi.2009, H. Morita (Malaise trap) (NK). Shiga: 2 males, Yuzurio, Eigenji, Higashi-omi, 12-31.v.2009, N. Kawase (Malaise trap) (MITR-20090419). Shikoku: Ehime: 2 males, same data as holotype (TN); 1 male, Izugatani-yama, Nishidani, Kumakogen-cho, 21.vi.2018, E. Yamamoto (light trap) (TN); 14 males, 1 female, same locality, 130.vi.2018, E. Yamamoto (Malaise trap) (TN); 7 males, 1 female, same locality, 1.vii-10.viii.2018, E. Yamamoto (Malaise trap) (SJP). Kochi: 1 male, 1 female, Nishikuma-rindo, Monobe-cho, Kami-shi, M. Takai (TN); 1 male, Befu-kyo, Monobe-cho, Kami-shi, 24.iv.2004, M. Takai (TN).

Etymology. This species is dedicated to Mr. Eiji Yamamoto, who gifted us valuable specimens, including specimens of this species.

Distribution. Japan (Honshu, Shikoku).

Remarks. This species was found from two major islands, Honshu and Shikoku, in Japan (Fig. 9). The genitalic characteristics are consistent in both populations, and there are stable differences between this species and a Korean species, $R$. kangae sp. nov.

\section{Rhyacophila confissa Botosaneanu 1970}

(Figs 2, 6, 9)

Rhyacophila confissa Botosaneanu 1970, 285-287, 326, 329, plate VI figs 1-5, plate IX figs 5-8, male, female.

Adult. Forewings each $10.0-11.5 \mathrm{~mm}$ in male $(\mathrm{n}=14), 11.5-12.1 \mathrm{~mm}$ in female $(\mathrm{n}=6)$. Ratio of width of eye to distance between eyes $0.23-0.31$ in male $(n=10), 0.21-0.25$ in female $(n=6)$.

Specimens examined. KOREA: 26 males, 3 females, Kangrimchon, Chiaksan National Park, Pugok-ri, Hoengsong-gun, Gangwon-do, 19.v.2000, T. Nozaki (net sweeping) (TN) ); 4 males, 3 females, Gombaeryeong, Bangtaecheon Stream, Jindong-ri 218, Girin-myeon, Inje-gun, Gangwon-do, 23.v.2018, MS. Kang (net sweeping) (SJP); 2 males, Jangjeon Valley, Jangjeon-ri 218, Jinbu-myeon, Pyeongchang-gun, Gangwon-do, 16.v.2015, MS. Kang (net sweeping) (SJP); 4 males, Byeongjibang Valley, Byeongjibang-ri, Gapcheon-myeon, Hoengsung-gun, Gangwon-do, 06.v.2016, MS. Kang (net sweeping) (SJP); 1 male, 2 females, Geumcheon Valley, Geumcheon-ri, Daapmyeon, Gwangyang-si, Jeollanamdo, 9.iv.2016, MS. Kang (net sweeping) (SJP).

Distribution. The Korean Peninsula (South Korea and North Korea). 

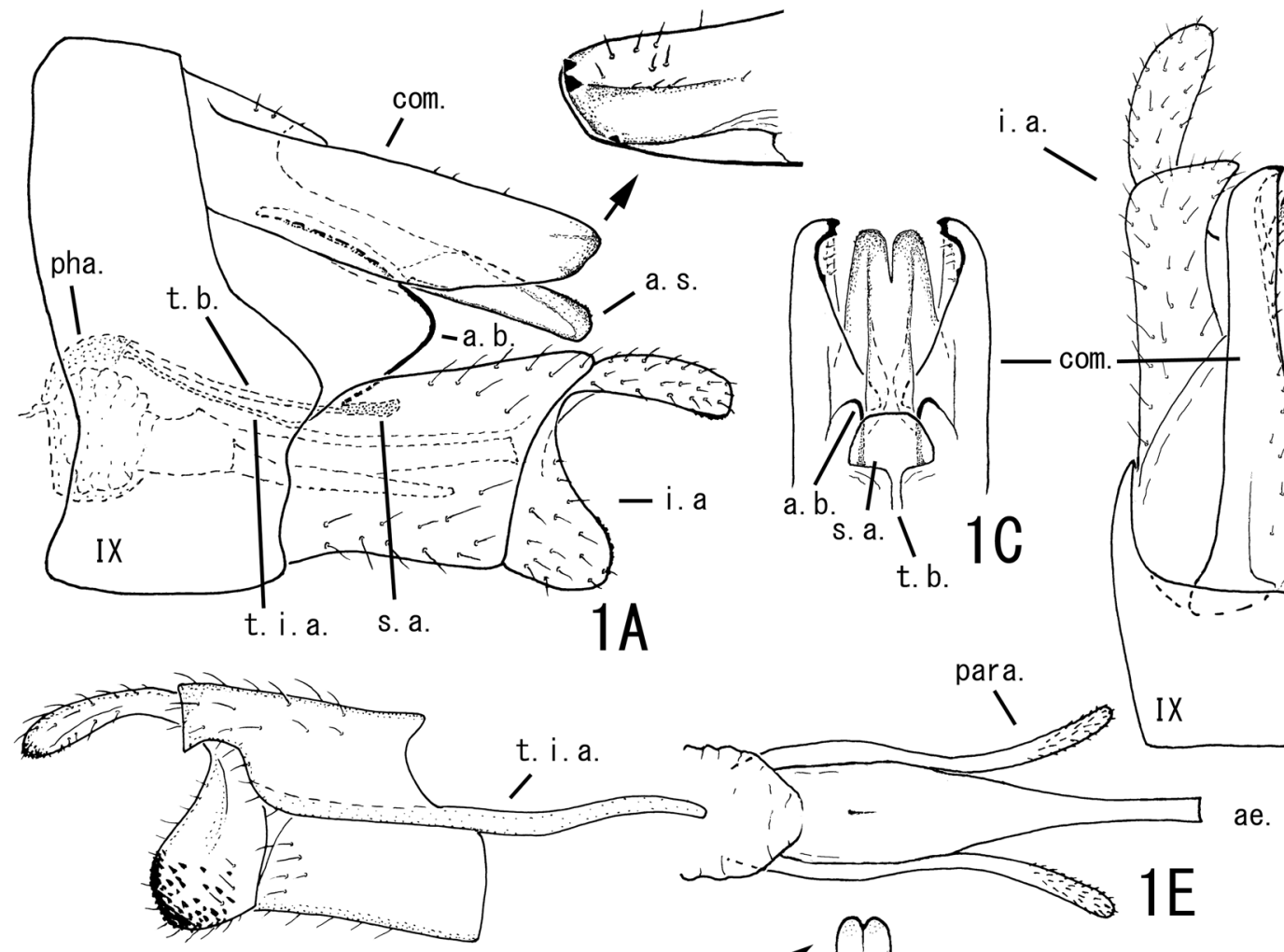

e.

a. s.

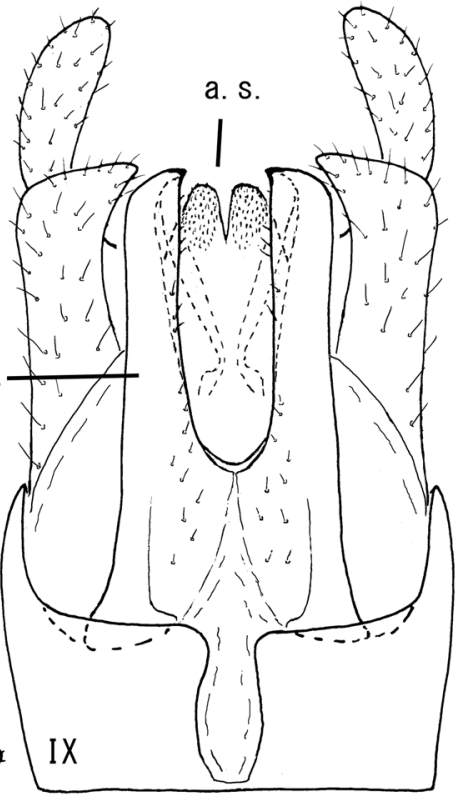

1B
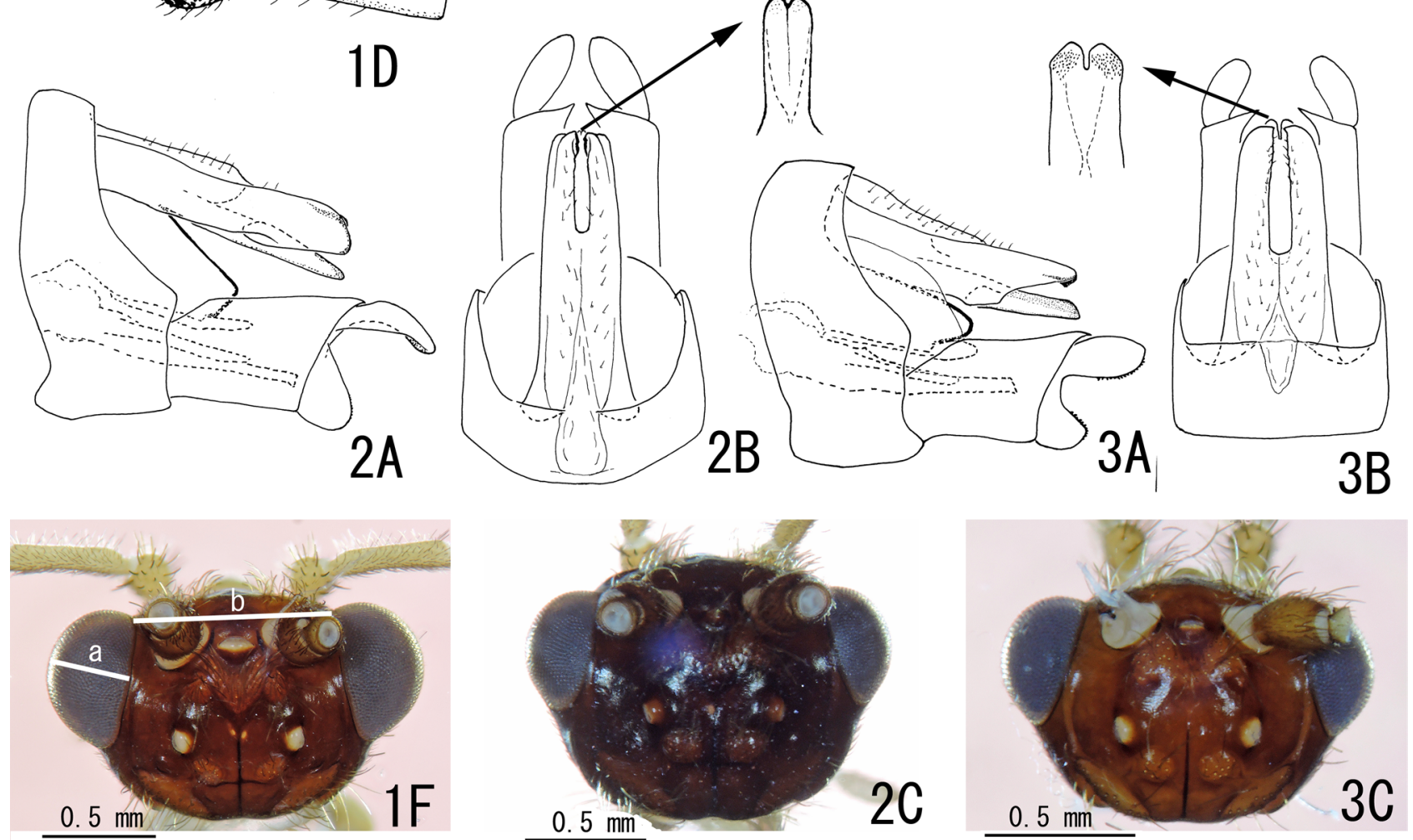

FIGURES 1-3. Rhyacophila spp., male. 1A-1F, Rhyacophila kangae sp. nov. 1A-1E, genitalia: 1A, left lateral, apicomesal part of complex of preanal appendages and apicodorsal lobe of segment IX enlarged; 1B, dorsal; 1C, upper part, ventral; 1D, left inferior appendage, mesal; 1E, phallic apparatus, dorsal. 1F, head, dorsal (a, b: see text). 2A-2C, Rhyacophila confissa Botosaneanu 1970: 2A, genitalia, left lateral; 2B, same, dorsal, anal sclerite enlarged; 2C, head, dorsal. 3A-3C, Rhyacophila vicina Botosaneanu 1970: 3A, genitalia, left lateral; 3B, same, dorsal, anal sclerite enlarged; 3C, head, dorsal. Abbreviations: a.b. = apical band, ae. = aedeagus, a.s. $=$ anal sclerite, $c$ com $=$ complex of preanal appendages and apicodorsal lobe of segment IX, i.a. = inferior appendage (paired), para. = paramere (paired), pha. = phallotheca, s.a. $=$ sagittal appendage, t.b. $=$ tergal band, t.i.a., $=$ tendon of inferior appendage (paired), IX = segment IX. 

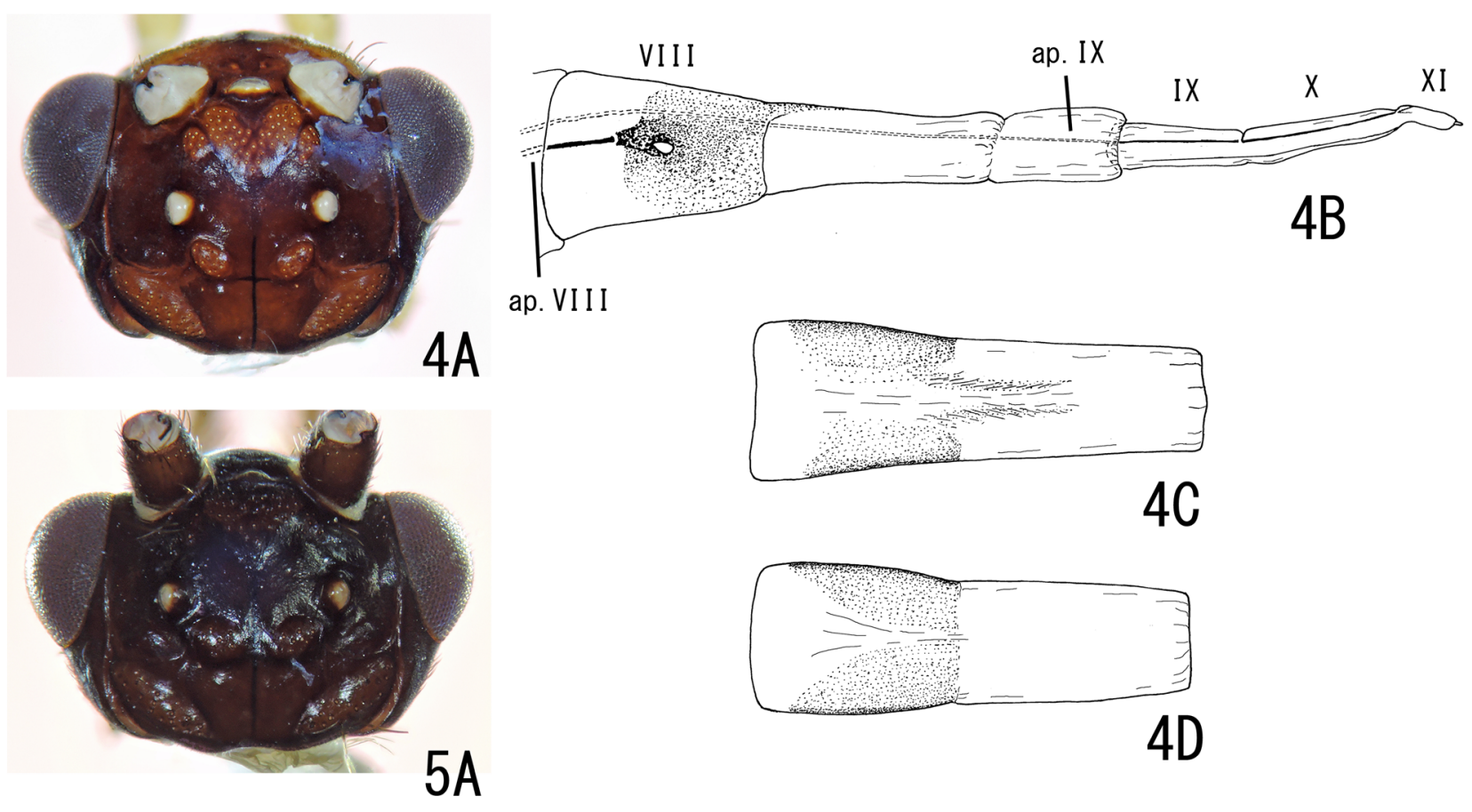

ap. VIII

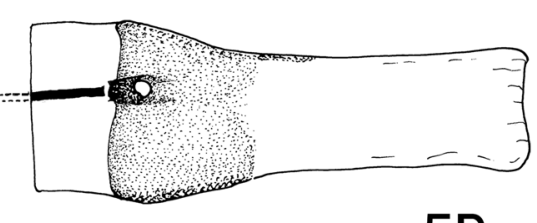

$5 B$

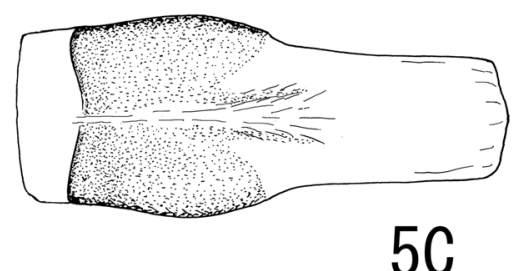

$5 \mathrm{C}$

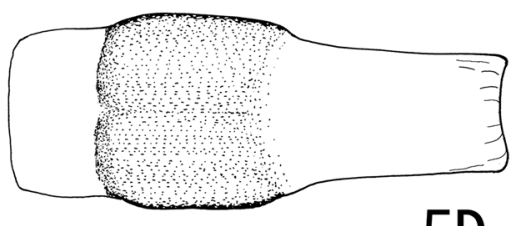

$5 D$
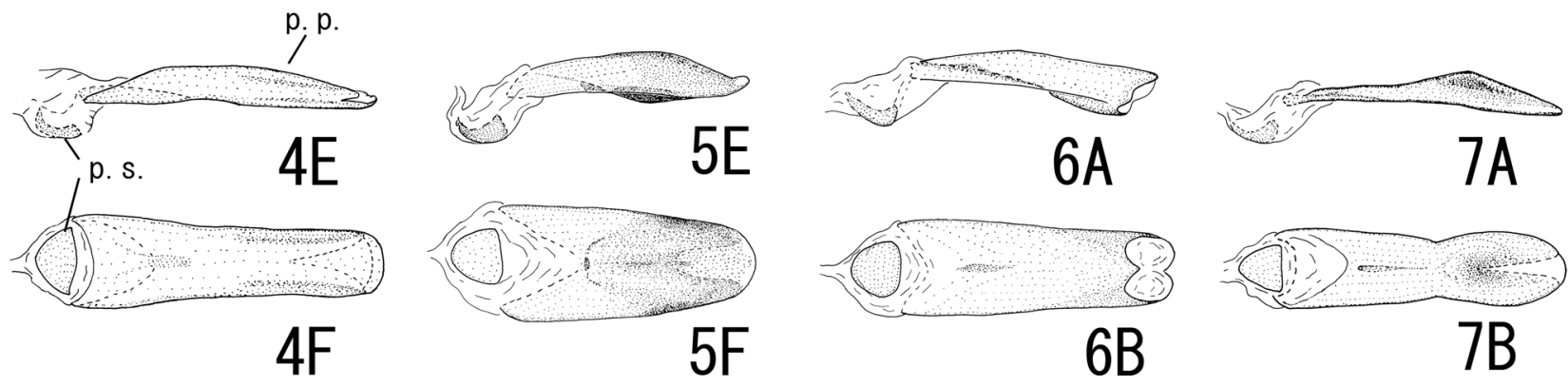

$6 \mathrm{~B}$

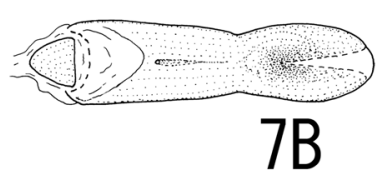

FIGURE 4-7. Rhyacophila spp., female. 4A-4F, Rhyacophila kangae sp. nov.: 4A, head, dorsal; 4B, abdominal segments VIII to XI, left lateral, 4C, abdominal segment VIII, dorsal; 4D, same, ventral; 4E, vaginal apparatus, left lateral; 4F, same, ventral. 5A-5E, Rhyacophila yamamotoi sp. nov.: 5A, head dorsal; 5B, abdominal segment VIII, left lateral; 5C, same, dorsal; 5D, same, ventral; 5E, vaginal apparatus, left lateral; 5F, same, ventral. 6A, 6B, Rhyacophila confissa Botosaneanu 1970: 6A, vaginal apparatus, left lateral; 6B, same, ventral. 7A, 7B, Rhyacophila vicina Botosaneanu 1970: 7A, vaginal apparatus, left lateral; 7B, same, ventral. Abbreviations: ap.VIII = apodemal rod of abdominal segment VIII (paired); ap.IX = apodemal rod of abdominal segment IX (paired); p.p. = posterior process; p.s. = processus spermathecae; VIII, IX, X, XI = abdominal segments VIII, IX, X, XI.

\section{Rhyacophila vicina Botosaneanu 1970}

(Figs 3, 7, 9)

Rhyacophila vicina Botosaneanu 1970, 287-288, 327, plate VII figs 1-6, male, female.

Rhyacophila jirisana Kobayashi, 1989, 4, 6, figs 3A, 3B, male. Synonymized by Nozaki et al. (2019). 
Adult. Forewings each $8.5-10.0 \mathrm{~mm}$ in male $(\mathrm{n}=12), 8.5-10.0 \mathrm{~mm}$ in female $(\mathrm{n}=8)$. Ratio of width of eye to distance between eyes $0.25-0.31$ in male $(n=12), 0.26-0.31$ in female $(n=8)$.

Specimens examined. KOREA: 2 males, 1 female, Kangrimchon, Chiaksan National Park, Pugok-ri, Hoengsong-gun, Gangwon-do, 19.v.2000, T. Nozaki (net sweeping) (TN); 2 males, Jomurak Valley, Gapyeong-gun, Gyeonggi-do, alt. 410 m, 2.vi.2014, T. Nozaki (net sweeping) (TN); 2 males, 1 female, Myeonji Mt. Valley, Gapyeong-gun, Gyeonggi-do, alt. 269 m, 2.vi.2014, T. Nozaki (net sweeping); 1 male, 1 female, Myeonji Mt. Valley, Gapyeong-gun, Gyeonggi-do, alt. 250 m, 3.vi.2014, T. Nozaki (light trap) (TN); 5 males, 5 females, Gwangchi Valley, Gaojak-ri, Yanggu-gun, Gangwon-do, 26.v.2015, MS. Kang (net sweeping) (SJP); 4 males, Sambong National Recreation Forest, Gwangwon-ri, Nae-myeon, Hongcheon-gun, Gangwon-do, 14.v.2018, MS. Kang (net sweeping) (SJP); Choamsa Temple, Jukgyegugok Valley, Baejeom-ri, Sunheung-myeon, Yeongju-si, Gyeongsangbuk-do, 1.vi.2013, MS. Kang (net sweeping) (SJP).

Distribution. The Korean Peninsula (South Korea and North Korea), Russia (South Primorye), China (Liaoning).

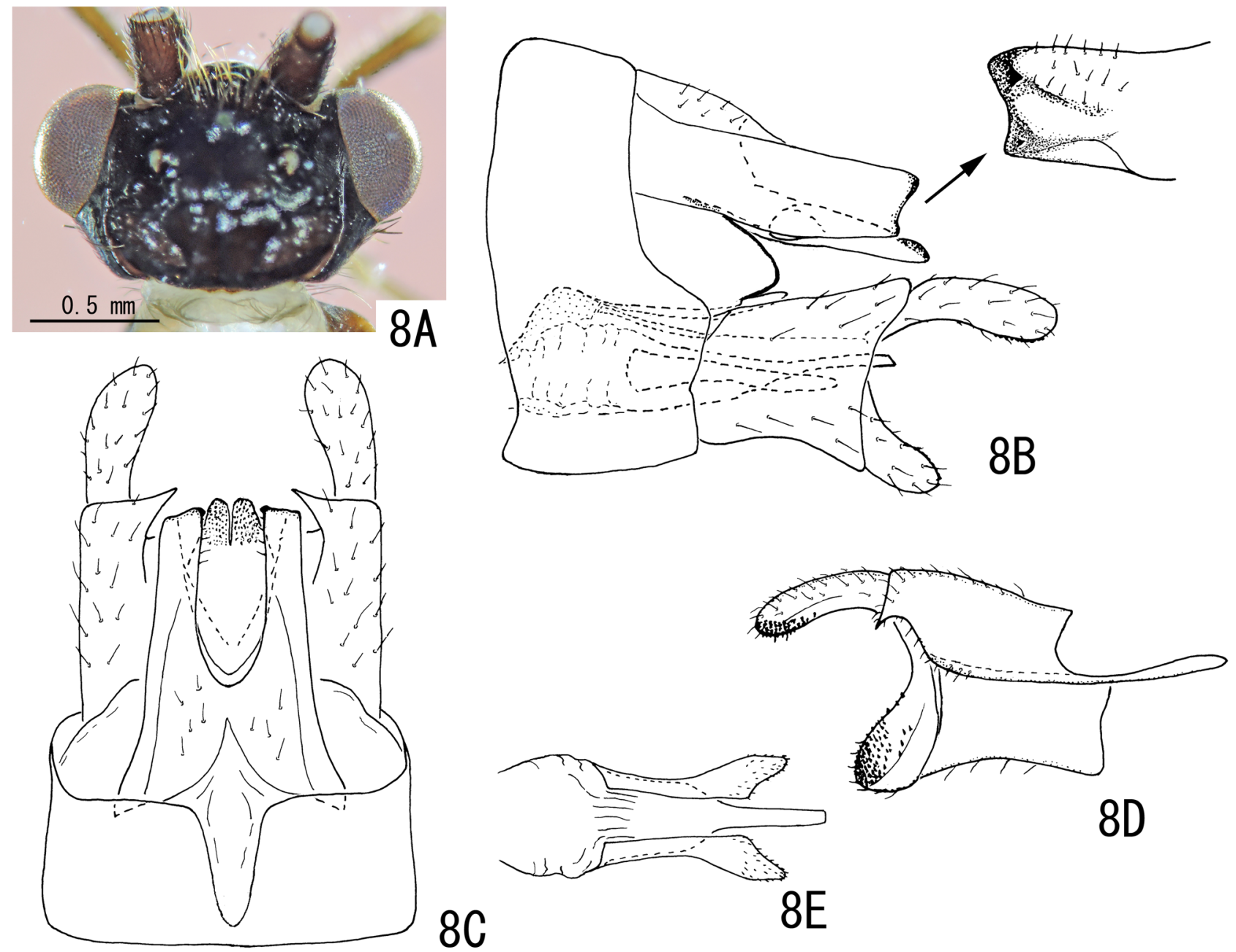

FIGURE 8. Rhyacophila yamamotoi sp. nov., male. 8A, head, dorsal. 8B-8E, genitalia: 8B, left lateral, apicomesal part of complex of preanal appendages and apicodorsal lobe of segment IX enlarged; $8 \mathrm{C}$, dorsal; $8 \mathrm{D}$, left inferior appendage, mesal; $8 \mathrm{E}$, phallic apparatus, dorsal.

\section{Acknowledgements}

We are grateful to the following persons for the loan or gift of valuable specimens: Dr Tomiko Ito, Hokkaido Aquatic Biology, Japan; Ms Mi-Sook Kang, SOKN, South Korea; Messrs Naoki Kawase, Minakuchi Kodomo-no-mori Nature Center, Japan; Hisayuki Morita, Yokkaichi-shi, Japan; Mikio Takai, Kami-shi, Japan; and Eiji Yamamoto, Yamamoto Institute of Forest Biology, Japan. We also cordially thank Dr. Pongsak Laudee, an anonymous reviewer, 
and the editor, Dr. John C. Morse for their valuable suggestions and comments to improve the manuscript. This work was supported by a grant from the National Institute of Biological Resources (NIBR), funded by the Ministry of Environment (MOE) of the Republic of Korea (NIBR201601203).

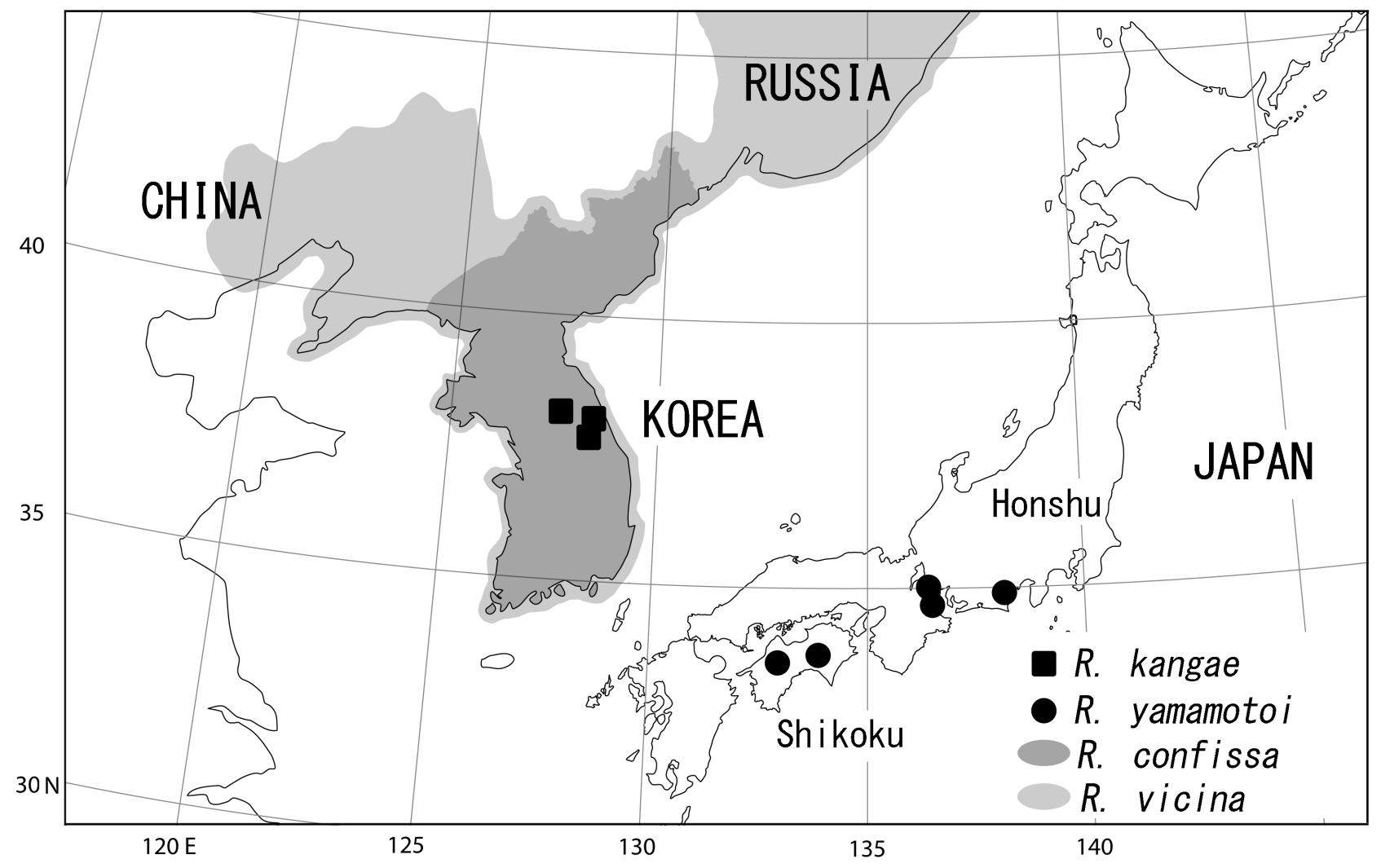

FIGURE 9. Distributions of 4 Rhyacophila species in East Asia. Distribution areas of $R$. confissa and $R$. vicina are cited from Ivanov (2011), Park \& Kong (2020), and Yang et al. (2016).

\section{References}

Arefina, T.I. (2001) An outline of females of the genus Rhyacophila (Trichoptera: Rhyacophilidae) from Eastern Asia. In: Bae, Y. J. (Ed.), The 21 ${ }^{\text {st }}$ Century and Aquatic Entomology in East Asia (Proceedings of the 1st Symposium of Aquatic Entomologists in East Asia). The Korean Society of Aquatic Entomology, Seoul, pp. 21-44.

Botosaneanu, L. (1970) Trichopteres de la Republique Democratique-Populaire de la Coree. Annales Zoologici, 27, $275-359$.

Hattori, T. (2005) Rhyacophilidae. In: Kawai, T. \& Tanida, K. (Eds.), Aquatic Insects of Japan: Manual with Keys and Illustrations. Tokai University Press, Kanagawa, pp. 414-437. [in Japanese]

Ivanov, V.D. (2011) Caddisflies of Russia: Fauna and biodiversity. Zoosymposia, 5, 171-209. https://doi.org/10.11646/zoosymposia.5.1.15

Iwata, M. (1927) Trichopterous larvae from Japan. Zoological Magazine, Tokyo, 39, 209-272. [in Japanese]

Kang, M.-S. (2020) The Korean caddisflies. Nature and Ecology, Seoul, 548 pp. [in Korean]

Kawase, N. \& Morita, H. (2010) The caddisfly (Insecta, Trichoptera) fauna of the Suzuka Mounatins. Biology of Inland Waters, 25, 31-50. [in Japanese with English abstract]

Kobayashi, M. (1989) A taxonomic study on the Trichoptera of South Korea, with description of four new species (Insecta). Bulletin of the Kanagawa Prefectural Museum Natural Science, 18, 1-9.

Martynov, A.V. (1918) Sur une nouvelle espèce de la tribu des Apataniini, et quelques autres formes provenant du Pays de Minoussinsk. Annuaire du Musèe Zoologique de l'Académie des Sciences de Russie, 22, 45-63. [in Russian]

Martynov, A.V. (1934) Tableaux Analytiques de la Faune de l'URSS. 13: Rucheyniki, Trichoptera, Annulipalpia, I. Institut Zoologique de l'Académie des Sciences, Leningrad, $343 \mathrm{pp}$.

Morita, H. (2009) Suzuka-sammyaku hokubu no tobikera-so [Trichoptera fauna of northern part of Suzuka Mountains]. Fujiwaradake, 31, 3-7. [in Japanese]

Morse, J.C. (Ed.) (2021) Trichoptera World Checklist. Available from: http://entweb.clemson.edu/database/trichopt/index.htm (accessed 18 August 2021)

Nozaki, T. (2021) Checklist of Japanese Trichoptera. Available from: http://tobikera.eco.coocan.jp/English/checklist.html (ac- 
cessed 18 August 2021)

Nozaki, T., Park, S.-J. \& Kong, D. (2019) Reexamination of five caddisfly species (Trichoptera, Insecta) recorded from South Korea by Kobayashi (1989). Animal Systematics, Evolution and Diversity, 35 (1), 1-5. https://doi.org/10.5635/ASED.2019.35.1.027

Park, S.-J. \& Kong, D. (2020) A checklist of Trichoptera (Insecta) of the Korean Peninsula. Journal of Species Research, 9 (3), 288-323. https://doi.org/10.12651/JSR.2020.9.3.288

Pictet, F.J. (1834) Recherches pour Servir à l'Histoire et à l'Anatomie des Phryganides. A. Cherbuliez, Geneva, 235 pp. https://doi.org/10.5962/bhl.title.8547

Ross, H.H. (1956) Evolution and classification of the mountain caddisflies. The University of Illinois Press, Urbana, Illinois, $213 \mathrm{pp}$.

Schmid, F. (1970) Le genre Rhyacophila et la famille des Rhyacophilidae (Trichoptera). Mémoires de la Société Entomologique du Canada, 66, 5-230, pls. 1-52. https://doi.org/10.4039/entm10266fv

Sun, C. (2017) Two new species of the Rhyacophila nigrocephala species group from China (Insecta, Trichoptera, Rhyacophilidae). European Journal of Taxonomy, 300, 1-10. https://doi.org/10.5852/ejt.2017.300

Tsuda, M. (1940) Zur kenntnis der Japanischen Rhyacophilinen (Rhyacophilidae, Trichoptera). Annotationes Zoologicae Japonenses, 19, 119-135.

Ulmer, G. (1927) Einige neue Trichopteren aus Asien. Entomologisch Mittelungen, 16, 172-182, pls. 5-6.

Yamamoto, E. \& Ito, T. (2014) Caddisflies (Trichoptera) collected from Izugataniyama, Kumakogen-cho, Shikoku, Japan in 2012-2013. Shikokukogera, 14, 6-21. [in Japanese].

Yamamoto, E., Nozaki, T., Kuhara, N. \& Ito, T. (2021) Caddisflies (Trichoptera) collected from a mountain stream, Namakusadani, in Shikoku, western Japan. In: Yamamoto Institute of Forest Biology (Ed.), Odamiyama no suisei-konchu to Matsubara-izumi no shizen, Uchiko-cho, Ehime. [in Japanese, in press]

Yang, L.F., Sun, C.H. \& Morse, J.C. (2016) An amended checklist of the caddisflies of China (Insecta, Trichoptera). Zoosymposia, 10, 451-479.

https://doi.org/10.11646/zoosymposia.10.1.42 